\title{
Social entrepreneurship as a tool for promoting critical, paradoxical learning in the field of business organization and management: An experiment from the University of Zaragoza
}

\author{
Ignacio Bretos $^{1}$, Millán Díaz-Foncea ${ }^{1}$, Clara Sarasa ${ }^{2}$, Alla Kristina Lozenko ${ }^{3}$, Carmen \\ Marcuello ${ }^{1}$ \\ ${ }^{1}$ Department of Business Organisation and Management, University of Zaragoza, Spain, \\ ${ }^{2}$ Department of Economic Structure, Economic History and Public Economics, University \\ of Zaragoza, Spain, ${ }^{3}$ Social Economy Laboratory, University of Zaragoza, Spain.
}

\begin{abstract}
There is a growing interest in examining subversive interventions by scholars that may involve the production of new subjectivities, the constitution of new organizational models, and the linking of these models with current social movements. This paper presents the case of the Social Economy Lab (LAB_ES), created in the Faculty of Economics and Business of the University of Zaragoza in 2017. In particular, we discuss the main experiences and interventions made from the LAB_ES around three areas of work: (1) the space of collective work; (2) the space of participation for the university community; and (3) the space of collective research. The study reflects the possibilities of including the study of alternative organizations in the education agenda. These organizations are guided by principles that include democracy, equality, emancipation and environmental sustainability. Likewise, the results and interventions of the LAB_ES are discussed not only to foster critical thinking among the students, but also to provide this group with skills for starting up alternative projects of organization and management outside the university. Finally, some key conclusions are drawn about the role of the $L A B \_E S$ as a space for collective research and collective production of critical knowledge about business organization and management, through the involvement of different actors.
\end{abstract}

Keywords: Alternative Economies, Critical Thinking, Knowledge Transfer, Paradoxical Thinking, Social Economy Organizations. 


\section{Introduction}

Especially since the outbreak in 2007/2008 of the last financial, social and humanitarian crisis of the capitalist system, we have witnessed a growing debate in the academic field about the teaching models and pedagogical content that dominate business schools and business schools, as well as the relevance and impact that research on organization and management has on real business practices (Rossi et al., 2017).

Specifically, these discussions have found special acceptance in the academic movement of the so-called Critical Management Education Studies (hereinafter CMES) (Alvesson et al., 2009). This branch of research poses a critique of the 'managerialist' and neoliberal ideology that permeates business schools and business science faculties and of the educational content taught, focusing on economic efficiency, business competitiveness and the dominant logic of 'profit maximization/cost minimization', thus emphasizing the marginalization of critical thinking about organizations that occurs daily in these spaces (Fotaki \& Prasad 2015). In this way, the CMES advocates politicizing, problematizing and making more complex the discussion on management in the educational field, addressing the influence that organizations and management practices have on economic and structural inequalities, systems of power relations and modes of domination and control, with the ultimate goal of imagining and generating more democratic, humanistic, emancipatory and socially responsible forms of management (Dehler 2009; Huault \& Perret 2011).

At the same time, the field of CMES has embarked on an in-depth debate about the gap between theory and practice, i.e. the relevance of Perret research and theory to influence or transform management and organizational practice (King \& Learmonth 2015; Cunliffe \& Scaratti 2017). These aspirations at the CMES level are part of a broader debate within the social sciences about how critical research and teaching can generate progressive change within society as a whole (Rossi et al., 2017). This discussion has crystallized into the concept of engaged scholarship, defined by Van de Ven \& Johnson (2006: 803) as 'a collaborative form of research in which scholars and practitioners use their different perspectives and skills to co-produce knowledge about a complex problem or phenomenon that exists under uncertain conditions in the world'. Committed scholarship' in the CMES field has taken different forms. These include the dissemination of knowledge beyond selfreferential academic circles (addressing not only senior management but also other stakeholders such as trade unions, workers, and minority and marginalised groups in society), the reformulation of academic conferences to promote more creative and dialogical engagement, and to encompass wider audiences (including policy makers), investors, activists or members of alternative organizations), or the involvement of academics as professionals and managers within organizations with the aim of actively influencing management practices and promoting broader social transformation (for a review, see King \& Learmonth 2015). 
However, as Fleming \& Banerjee (2016) point out, a much less explored line of work by the CMES school to advance the understanding of 'committed scholarship' lies in the critical pedagogy of management in educational spaces. This is paradoxical considering that, as illustrated by several works based on critical pedagogy, offering tools to students to think and reflect critically on management is essential to promote emancipatory and constructive social actions, and thus transform the practical reality of management (among others, Dehler 2009; Huault \& Perret 2011). Indeed, some authors suggest that it is essential to explore how 'engaged scholarship' can be associated with practices of educational innovation and collective knowledge co-generation that encourage students to learn about alternative forms of entrepreneurship and to become involved in the organizational and management practices that take place in their environment (Cunliffe \& Scaratti 2017).

To this end, the experience of the Social Economy Laboratory (LAB_ES) of the Faculty of Economics and Business of the University of Zaragoza is presented, a space created in 2017 to experiment with the social economy on the part of the university community, that is, a place where the students, the PDI and the PAS can practice with economic projects based on the principles of Participation, Mutual Support, Solidarity and Commitment to the environment, within the framework of the University and in contact with the business and association reality of this sector.

\section{Context}

The LAB_ES was formally created at the beginning of 2017 as a result of the collaboration of professors from the Department of Business Management and Organisation, administration and service personnel and students from the faculty. On the one hand, it was observed that in the Faculty of Economics and Business of the University of Zaragoza there was no space open to all groups of the university community in which to promote and disseminate knowledge about the Social Economy sector. On the other hand, shortcomings were also detected among the faculty's students, related to the lack of skills in two very specific areas: (i) in the capacity for teamwork and cooperation and (ii) in the development of values that provide their professional and academic activity with a sense and capacity for critical analysis of the reality studied and its environment.

In this way, the LAB_ES was designed to try to address both shortcomings. Thus, the space stands as a reference point for the development of socially responsible, ecologically sustainable and economically viable projects, aimed at students, teaching and research staff and administration and services staff of the Faculty of Economics and Business as a whole. Focusing on the students, the final objective is to provide this group with tools, skills and abilities to work as a team, to apply in a practical way the knowledge acquired in the degree, as well as to get to know the social and economic environment from a different 
point of view and to be able to meet the needs of social economy entities once their stay at the University is over. The LAB_ES complements the training offered in the degree, encouraging the development of a critical and constructive spirit with reality. Likewise, the LAB_ES is established as a space for the PDI and the PAS to develop innovative collective practices and design new teaching methodologies linked to the transfer of knowledge and work close to the students and social entities of the city. The projects and ideas to be developed in the LAB_ES must respect the following premises:

- $\quad$ It must be promoted from the principles and values of the social economy

- $\quad$ It must focus on the implementation of real projects

- It must promote Knowledge Transfer

- It must generate social innovation

- It must obtain a positive social impact for society

The conviction with which the LAB_ES originates is that the organisations of the Social Economy, i.e. cooperatives, mutual societies, labour companies, insertion companies, special employment centres, associations, foundations and agricultural transformation companies (Bretos \& Marcuello, 2017), propose a fairer alternative to the traditional capitalist enterprise, as they are based on principles of a social nature such as the primacy of the person and the social purpose over capital, the defence and application of the principles of solidarity and responsibility, democratic governance, or autonomy of management and independence, among others (Bretos \& Errasti 2017).

\section{Results}

The project has achieved various results, which can be grouped according to the three key spaces that make up the work developed from the LAB_ES. These are the Collective Work Space, the Participation Space of the University Community and the Collective Research Space. It should be noted that these three spaces are enhanced and complemented thanks to the involvement of the LAB_ES team, the collaborating entities and all the users who have passed through them, contributing their time, ideas or work.

\subsection{Space of collective work}

The Collective Work Space is designed to develop its own projects or to collaborate in other projects of Social Economy entities. The main lines of action developed so far, as well as the main results obtained, are described below.

Development of the project ApS Social Business Consultancy: The objective of this project is to offer new training spaces to the students of the University of Zaragoza, combining social commitment, training, collective reflection and the implementation of their academic knowledge in order to develop social projects at the service of people and groups in a 
disadvantageous situation. In this way, the aim is to train socially responsible, ethically prepared business and economics students who are capable of integrating social and environmental aspects into their management and relationship skills, taking as a reference model the Business Social Consultancy developed by the University of Comillas (ICADE). The project was defined specifically through a Teaching Innovation Project based on service learning, which is structured around two main axes: training in economics and business at the service of people, which translates into the implementation of a mobile basic economics school for disadvantaged groups, inclusive businesses, social entrepreneurs, insertion companies, etc., and action on specific social needs, in which students make the knowledge they have acquired during their degree available to participating entities. Along these lines, regulations have been drawn up for the academic structure of the programme and an agreement has been formalised with the ADUNARE Foundation, which manages the Social and Labour Centres of the Zaragoza City Council, and which provides a wide range of users to attend to, being able to select those groups that are most suited to those tasks for which the students are most predisposed.

University Social Innovation Award: In order to recognise and support innovative initiatives linked to the Social Economy and developed by the university community, the first edition of the University Social Innovation Award was announced. In this way, the aim was to promote new ways of satisfying social needs that are not adequately covered by the market or the public sector, constituting new social relations that place people at the centre of their activity and always within the framework of the University of Zaragoza. The Award was attended by 16 people, who developed and disseminated a total of 9 socially innovative projects on social networks.

\subsection{Space of participation for the university community}

Through this space, the aim is to promote the empowerment of the university community through Social Economy projects, to carry out activities based on the transfer of knowledge to society and to initiate processes to learn about the consumption patterns of a localised group that will allow us to promote responsible habits among them that are respectful of the environment and society. So far, the following initiatives have been developed:

Events at the Faculty of Economics and Business of the University of Zaragoza: Taking advantage of the start of the 2017/2018 academic year and the institutional launch of the LAB_ES, an event was held to present the Social Economy Laboratory, with a twofold objective: to publicise the existence of the Laboratory and all its activities, and to disseminate the work of Aragonese Social Economy entities, bringing them closer to the university community in a dynamic and attractive way. To this end, the event was divided into three spaces: LAB_ES Conference Space, Exhibition Space, Gastro Space. The events were attended by 15 collaborating entities and took place over a whole day in the Faculty of 
Economics and Business of the University of Zaragoza, with the aim of reaching 578 potential participants. In addition, thanks to the collaboration of Oxfam Intermón, every Wednesday during the months of November and December 2017 the principles of Fair Trade were disseminated in different locations and on the Campus of the Faculty of Economics and Business, offering a solidarity tasting of coffee, cocoa and cookies and thus taking a first step towards mobilizing and changing practices and attitudes towards consumption.

Seedbed of Ideas: This is an initiative aimed at the students of the Faculty of Economics and Business of the University of Zaragoza in order to provide them with a space in which to think about and develop projects and initiatives linked to the Social Economy based on participation, mutual support, solidarity and commitment to the environment. Since the beginning of 2017, weekly meetings have been held that are open to anyone who wants to get to know the LAB_ES, propose ideas and learn by doing. Throughout the year, these meetings led to participation in the Cineforum organised by the Delegation of Students from the Faculty of Economics and Business of the University of Zaragoza and to the preparation, dissemination and analysis of a survey on Responsible Consumption with the aim of finding out about the consumption patterns of the university community, in order to carry out a task of communication and dissemination of the alternatives and initiatives of awareness and promotion of responsible consumption existing in the city.

I University-ESS Meeting: In order to learn about and connect the projects for promoting the Social and Solidarity Economy that already exist in other universities, as well as to develop the potential of the University as a key institution for the development of the Social and Solidarity Economy, the I University-ESS Meeting was organised, promoted and held in December 2017. The Meeting, which was organised around the themes of Training, Research and Territory, tackled two fundamental challenges: how to attract or involve the university community in the Social and Solidarity Economy and how to create spaces and methods that favour collaboration between the University and the business and association reality of the sector. The Meeting was held in collaboration with other universities and seven entities linked to the Social Economy, and welcomed 40 participants from Madrid, Catalonia, Andalusia, Valencia, Galicia and Aragon.

\subsection{Space of collective research}

The objective of this axis or space is to create, promote and make visible useful resources for knowing and recognising the Social Economy. Along these lines, three research projects have been carried out in order to highlight the value of the Social Economy and to establish a methodology for possible future exports.

Directory of Social Economy Entities: In order to unify and complete the existing information on the Social Economy Entities that are federated into representative 
organisations, the Directory of Entities drawn up by CEPES Aragón in 2012 has been updated. To this end, data has been collected through the networks or platforms in which the bulk of Social Economy Entities in Aragon are located. Once the information has been unified and the missing data has been filled in by means of manual searches in specialised databases and on the websites of the entities themselves, a database has been created with the data referring to: platforms to which they are adhered, date of constitution, legal form, activity, number of employees, number of members, number of volunteers, invoicing data and contact data.

Cooperative Entrepreneur in Zaragoza: The objective of the second of the research works carried out in 2017 was to analyse the reality of the Cooperative Entrepreneur in Zaragoza, in order to know the number and main characteristics of the Associated Work Cooperatives, a sector that is not federated and about which there is no data. In order to know the evolution of the cooperative sector, the Associated Work Cooperatives created between 2011 and 2017 were analysed, creating a database and a virtual map of them that covers the city of Zaragoza as well as the rural neighbourhoods and municipalities of the province.

\section{Conclusions}

This paper has presented the case of the Social Economy Lab (LAB_ES). In particular, we have discussed the main experiences and interventions made from the LAB_ES around three areas of work: (1) the space of collective work; (2) the space of participation for the university community; and (3) the space of collective research. The study reflects the possibilities of including the study of alternative organizations to promote paradoxical and critical thinking in the field of business organization and management. These organizations are guided by principles that include democracy, equality, emancipation and environmental sustainability. Likewise, the results and interventions of the LAB_ES have provided students and praticipants with skills for starting up alternative projects of organization and management outside the university. Finally, it is also remarkable the role of the LAB_ES as a space for collective research and collective production of critical knowledge about business organization and management, through the involvement of different actors such as teaching staff, students, practitioners and policy-makers.

The paper is relevant to further understand not only the harmful effects of mainstream neoliberal economic and managerial education (Ghoshal, 2005), but most importantly how the study of social entrepreneurship and alternative organizations can allow us rethinking social responsibility and caring in economics and business organization. In addition, the work contributes in two directions to advance our understanding of the role of 'committed scholarship' in the field of CMES. On the one hand, the work shows the potential offered by the study of alternative organizations not only to promote critical thinking among students, 
but also to make them capable of carrying out alternative experiences of organization and management outside the university, based on aspects such as dignity, social justice, welfare and environmental sustainability. On the other hand, the work shows how the participation of diverse social actors (students, faculty, administration and service personnel, policymakers and practitioners) in teaching and research projects can help reduce the gap between theory and practice, favoring the creation of critical, useful, relevant and practical knowledge for society that serves as a catalyst for developing subversive and emancipatory interventions in real organizational life.

\section{References}

Alvesson, M., Bridgman, T., \& Willmott, H. (2009). The Oxford Handbook of Critical Management Studies. Oxford: Oxford University Press.

Bretos, I., \& Errasti, A. (2017). Challenges and opportunities for the regeneration of multinational worker cooperatives: Lessons from Mondragon Corporation - A case study of the Fagor Ederlan Group. Organization, 24(2), 154-173.

Bretos, I., \& Marcuello, C. (2017). Revisiting globalization challenges and opportunities in the development of cooperatives. Annals of Public and Cooperative Economics, 88(1), 47-73.

Cunliffe, A. L., \& Scaratti, G. (2017). Embedding impact in engaged research: Developing socially useful knowledge through dialogical sensemaking. British Journal of Management, 28(1), 29-44.

Dehler, G. E. (2009). Prospects and Possibilities of Critical Management Education: Critical Beings and a Pedagogy of Critical Action. Management Learning, 40(1), 31-49.

Fleming, P., \& Banerjee, B. (2016). When Performativity Fails: Implications for Critical Management Studies. Human Relations, 69(2), 257-276.

Fotaki, M., \& Prasad, A. (2015). Questioning neoliberal capitalism and economic inequality in business schools. Academy of Management Learning and Education, 14(4), 556-575.

Ghoshal, S. (2005). Bad management theories are destroying good management practices. Academy of Management Learning \& Education, 4(1): 75-91.

Huault, I., \& Perret, V. (2011). Critical management education as a vehicle for emancipation.M@n@gement, 14(5), 281-309.

King, D., \& Learmonth, M. (2015). Can critical management studies ever be 'practical'? A case study in engaged scholarship. Human Relations, 68(3), 353-375.

Rossi, F., Rosli, A., \& Yip, N. (2017). Academic engagement as knowledge co-production and implications for impact: Evidence from Knowledge Transfer Partnerships. Journal of Business Research, 80, 1-9.

Van de Ven, A. H., \& Johnson, P. E. (2006). Knowledge for theory and practice. Academy of Management Review, 31, 802-821. 